\title{
Effect of Lameness on Culling in Dairy Cows
}

\author{
C. J. Booth, ${ }^{1}$ L. D. Warnick, ${ }^{1}$ Y. T. Gröhn, ${ }^{1}$ D. O. Maizon, ${ }^{2}$ \\ C. L. Guard, ${ }^{1}$ and D. Janssen ${ }^{1}$ \\ ${ }^{1}$ Department of Population Medicine and Diagnostic Sciences, and \\ 2Department of Animal Science, Cornell University, Ithaca, NY 14853
}

\begin{abstract}
The purpose of this study was to assess the effect of lameness on dairy cow survival. Cox's proportional hazards regression models were fitted to single-lactation data from 2520 cows in 2 New York State dairy herds. Models were controlled for the time-independent effects of parity, projected milk yield, and calving season, and for the time-dependent effects of lameness and culling. Other common diseases were found to be nonconfounding and so were not included in any of the final models. Survival was measured as the time from calving until death or sale. Cows were censored if they reached the start of the next lactation or end of the study, whichever occurred first. All models were stratified by herd. For all lameness diagnoses combined, survival in the herd decreased for those cows becoming lame during the first half of lactation, with a hazard ratio of up to 2 times that of a nonlame cow. Foot rot diagnosed during the second or third months of lactation decreased survival during the same time period (hazard ratio $=5.1 ; 95 \%$ confidence interval $=1.6$ to 16.2). Sole ulcers diagnosed in the first 4 mo of lactation decreased survival in several subsequent periods in which the strongest association was between diagnosis in the third and fourth months of lactation and exit from the herd during that same period (hazard ratio $=$ 2.7; $95 \%$ confidence interval $=1.3$ to 6.0 ). Foot warts were not associated with decreased survival in this analysis. Lameness was never associated with increased survival in any of the models.

(Key words: lameness, culling, survival analysis, timedependent covariates)
\end{abstract}

Abbreviation key: M305 = 305-d projected milk yield .

\section{INTRODUCTION}

Lameness in dairy cows is second only to mastitis in terms of its detrimental effect on herd productivity

Received April 19, 2004.

Accepted September 13, 2004.

Corresponding author: L. D. Warnick; e-mail: ldw3@cornell.edu.
(Esslemont and Kossaibati, 1996). As well as productivity losses, lameness severely compromises the welfare of affected animals and is probably the single most common cause of distress in dairy cattle (Webster, 1986). Its annual incidence ranges between 4 and 55 cases per 100 cows per yr, depending on farm, location, and year of study (Leech et al., 1960; Prentice and Neal, 1972; Eddy and Scott, 1980; McLennan, 1988; Clarkson et al., 1996; Whitaker et al., 2000). Lameness decreases milk yield (Rajala-Schultz et al., 1999; Warnick et al., 2001) and fertility (Lucey et al., 1986; Collick et al., 1989; Lee et al., 1989; Hernandez et al., 2001), and increases the risk of culling (Collick et al., 1989; Esslemont and Kossaibati, 1997). Therefore, the ultimate cost of a case of lameness is substantially greater than treatment costs alone. Kossaibati and Esslemont (1997) predicted an overall cost of $£ 246.22$ per case (approximately US $\$ 446$ ) in the United Kingdom.

Effect of lameness on culling is not clear-cut, because several authors have reported little or no increase in culling due to lameness (Dohoo and Martin, 1984; Milian-Suazo et al., 1988; Barkema et al., 1994; Beaudeau et al., 1994, 1995). The decision to cull a cow is complicated, with many factors influencing that decision, notably, age (parity), milk production, fertility, and health (Gröhn et al., 1998). Additional factors, such as seasonal variations, input and output prices, and other variables influence culling (Van Arendonk, 1985; Van Arendonk and Dijkhuizen, 1985). Numerous variables, therefore, should be considered in an analysis of lameness effects on culling.

The objective of this study was to estimate the effects of lameness in general and of specific clinical diagnoses of lameness on survival in the herd.

\section{MATERIALS AND METHODS}

\section{Study Farms and Data Collection}

The study used records from 2 farms located near Ithaca, New York, collected between June 1, 1997, and December 31, 1998, as previously described by Warnick et al. (2001). Data were collected on 1796 cows in herd A and 724 cows in herd B. Almost all cows in the study were Holsteins and were housed in free-stall barns. 
Milking occurred 2 or 3 times daily in milking parlors. Recombinant bovine somatotropin (rbST) was used on both farms; herd A injected bST every 2 wk after 76 DIM until 2 wk before milking was terminated (dry period). Herd B injected bST every 2 wk starting after 80 DIM until $30 \mathrm{~d}$ before the dry period. Milk production was recorded using automated milking systems: herd A used ALPRO milking equipment (DeLaval Inc., Kansas City, MO), and herd B used Afimilk meters (S.A.E. Afikim, Israel). These records were transferred to DairyComp 305 (Valley Agricultural Software, Tulare, CA) and then obtained at approximately weekly intervals for further analyses.

Farm workers diagnosed and treated lame cows in herd A. In herd B, lame cows were identified by farm workers or by a professional foot trimmer who visited the farm monthly. In herd A, a lame cow was defined as one that was selected for lameness treatment. In herd B, a lame cow was one with a lesion of the foot or overgrowth of the hoof wall as identified by the hoof trimmer, or as a cow treated for lameness by farm workers. Lameness records were collected on paper weekly at herd A and on paper or on computer at herd B. Causes of lameness in both farms were described as abscess (white line and sole abscesses), sole ulcer (pododermatitis circumscripta), foot rot (interdigital phlegmon), foot warts (digital dermatitis), or other.

Sole ulcers included necrotic and degenerative sites in the sole near the sole-heel junction. Foot rot described swelling above the coronary band and spreading of the toes that sometimes resulted in necrosis of tissue between the toes. In herd A, interdigital dermatitis and interdigital hyperplasia were coded as foot rot. Foot warts were ulcerative or proliferative lesions of the digits or interdigital regions with a red or gray roughened surface. Other diagnoses included miscellaneous conditions such as heel cracks, hoof overgrowth, laminitis, stones in the foot, and upper limb problems. For the purposes of these analyses, abscesses were combined with the "other" category.

Culling and other cow-event data were collected on a backup computer disk from farm computers at approximately weekly intervals during the study. Exit from the herd occurred by death or sale, both of which were referred to as culling. Sale accounted for approximately 80 to $85 \%$ of cows leaving the herds. Data were transferred to The Survival Kit, a Fortran statistical package (Ducrocq and Sölkner, 1998) for analysis. Lameness events included in the data were those that occurred after the first calving event in the study and before culling, the next calving, or the end of the study, whichever occurred first. Second and further lameness events involving the same cow during lactation were excluded from the analysis.

\section{Variables and Covariates}

The dependent variable was the number of days from calving to culling. Cows that were not culled during the study were censored at the start of their next lactation or at the end of the study, December 31, 1998, whichever occurred first.

Calving season, parity, and 305-d projected milk yield (M305) were covariates considered to control for confounding effects. Calving season classes were created: December-February; March-May; June-August; and September-November. Parity groups included: 1, 2, 3, and $\geq 4$. The first M305 available during the study was used as an estimate of potential milk yield. For $92.5 \%$ of cows, the M305 value used was predicted within the first 30 DIM, and for $99 \%$ of cows the M305 estimate was from within 257 DIM. The categories created for M305 were $\leq 6356,6357$ to 7264,7265 to 8172,8173 to 9080 , and $>9080 \mathrm{~kg}$, and missing values. (These classes were numbered from 1 to 6 , respectively). Missing values were those for which no M305 data were available, but yet it was known these cows were in the milking herd (but were possibly diseased or culled early) during the study. Missing values were recorded for 157 cows in herd A and 15 cows in herd B (total of 172 of 2520 cows or $6.8 \%$.)

Cases of clinical mastitis, retained placenta, clinical ketosis, left-displaced abomasum, and milk fever that occurred during the study were assessed as possible confounders for the effect of lameness on culling. These diseases were diagnosed and recorded by farm personnel or herd veterinarians according to usual farm practices (no attempt was made to standardize their definitions between herds).

\section{Statistical Analyses}

Crude associations of parity, calving season, and projected milk yield with lameness and culling were tested (using StatExact-3 version 3.0.2, StatXact 3 for Windows User Manual, 1996). The Cochran-Armitage trend test was used for analyses of parity or projected milk yield category. $\chi^{2}$ was used to test the significance of associations with calving season.

Effect of lameness on culling was analyzed using survival analysis. Cox's proportional hazards models (Cox, 1972) were fitted using The Survival Kit (Ducrocq and Sölkner, 1994, 1998). The hazard of an event at time $t$ was the probability that the event occurred, given it did not occur before time $t$. The Cox's proportional hazards model assumes that the ratio of hazards of 2 groups remains constant during the whole study, and does not specify the underlying survival function.

Lameness was modeled as a whole (i.e., combining sole ulcers, foot rot, foot warts, and other) and for each 
diagnosis individually. Assuming that occurrence of lameness and culling varied depending on the interval since calving, lameness events were classified based on when they occurred after calving: $\leq 60,61$ to 120,121 to 240 , and $>240 \mathrm{~d}$ (designated as periods 1 to 4 , respectively). On the other hand, the period from calving to culling was considered to be a piecewise constant function of time with cut-off points at 60,120, and $240 \mathrm{~d}$ after calving. These periods were called stages of lactation, and numbered from 1 to 4, respectively. In addition, to consider that the hazard of culling for a cow that experienced lameness at any time may not remain constant over time, the effect of lameness on culling was modeled by the interaction of the time-dependent covariates of lameness and stage of lactation, using the approach of Gröhn et al. (1997). Assuming an interaction between time of lameness and time of culling results in more accurate, detailed estimates of the effect of lameness on culling. All periods ( $\leq 60 \mathrm{~d}, 61$ to 120 d, etc.) were evaluated in the same model. No cows, therefore, were discarded from the analysis.

Five models were fitted in this study, each containing slightly different explanatory variables for lameness. These models attempted to assess the effect on culling of lameness as a whole (model 1), foot rot (model 2), foot warts (model 3), sole ulcers (model 4), and other diagnoses of lameness (model 5), respectively. When 1 of the last 4 diagnoses was fitted, the other 3 diagnoses were combined in an explanatory variable accounting for their effect on culling. Models included calving season, parity, and M305 as fixed effects, and the selected diagnosis of lameness and other diseases as time-dependent covariates. All comparisons were made against first-lactation cows that calved during winter, belonged to the highest level of M305, and were not diagnosed with disease. All models were stratified by herd.

Pregnancy status and other measures of fertility were not included in the model. Although numerous studies have found that infertility is correlated positively with culling, and lameness may decrease fertility indices, pregnancy status presumably has little effect on the prevalence of lameness. Therefore, pregnancy status was assumed to be an intervening variable (i.e., lameness affects fertility) that may affect risk of culling, but ultimately the increased risk is because of lameness. By including such variables in the model, the effect of lameness on culling would have been underestimated.

\section{RESULTS}

\section{Summary of Data}

Table 1 summarizes the data analyzed in the study. Herd A had more than twice as many lactating cows in the study as herd B (1796 and 724 cows respectively); combining the herds created a data set of 2520 cow lactations. About two-thirds of each herd were in their first or second lactation. Most cows enrolled in the study calved during summer and autumn (57\% herd A and $58 \%$ herd B). This was, in part, due to the inclusion of 2 summer and autumn seasons in the study enrollment period. A total of 1212 cows were diagnosed lame at least once during the observation period ( $48 \%$ of cows enrolled). Among lame cows, $45 \%$ were diagnosed lame only once, $23 \%$ twice, $12 \% 3$ times, and $20 \%$ were diagnosed as lame 4 or more times. In herd A, incidence of lameness was $52 \%$ during the study, compared with $40 \%$ in herd B. Distribution of first lameness events by diagnosis and stage of lactation is shown in Table 2. Foot rot and lameness categorized as "other" diagnoses tended to occur earlier in lactation than sole ulcers or foot warts. Other descriptive statistics for the 2 herds were reported previously. Note that differences from that earlier report in the distribution of diagnoses in herd A resulted from an alternative way of handling multiple diagnoses for the culling analysis (Warnick et al., 2001).

Without adjusting for potential confounding variables, lameness was more common in older cows and among cows with greater M305 $(P<0.001)$, but was not associated with calving season. The percentages of cows culled during the study were greater $(P<0.001)$ for older cows, lesser $(P<0.001)$ for cows having greater M305 and were associated with calving season $(P<$ 0.01). Parity, calving season, and M305 were included in the multivariable models of lameness effects on culling to control for the potential confounding effects of these factors.

\section{Milk Yield, Parity, and Calving Season}

Cows in the first 4 M305 categories were culled earlier than those in the highest M305 category. The culling hazard for the lowest producers was 15 times greater than the baseline group (Table 3 ). In analyses of models 1 to 5 , the time-independent variables forced into the model were M305, parity, and calving season. Cows without an M305 (i.e., missing data) were culled earlier than cows in the highest M305 category. It is likely these cows were those culled before the M305 was calculated, so their risk of being culled was, by definition, greater than that of a baseline group.

Increasing parity was associated with an increased culling hazard compared with first-lactation cows. The hazard ratio for cows in lactation 4 or above was approximately 5 compared with control cows (Table 3). Cows in their second and third lactation were intermediate in culling risk. Cows calving during summer and au- 
Table 1. Frequency distributions for all cows, cows diagnosed lame, and cows culled during the study for 2 New York dairy herds (column percentages of the total number of cows, lame cows, or cull cows are shown in parentheses).

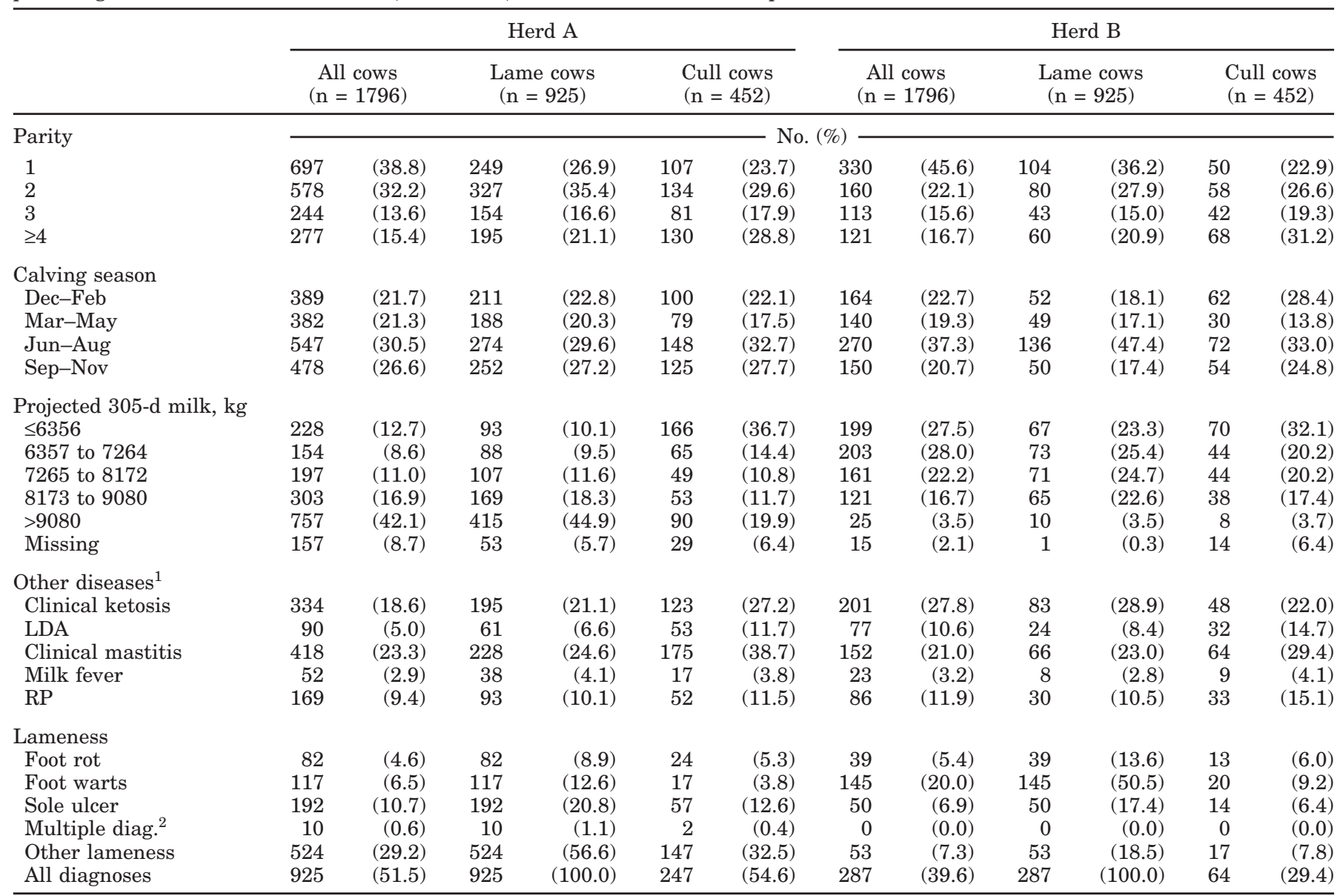

${ }^{1} \mathrm{LDA}=$ Left-displaced abomasum; RP = retained placenta.

${ }^{2}$ Multiple diagnoses (among foot rot, foot warts, and sole ulcer) recorded for first lameness event. Cows with multiple other diagnoses are included in "other lameness."

tumn had reduced culling risk compared with those calving in winter. The culling hazard for spring-calving cows was not different from that for winter-calving cows.

\section{Lameness and Culling}

Effect of lameness on culling is described in models 1 to 5 (Table 4). It must be noted that all nonlameness

Table 2. Diagnosis by stage of lactation for the first occurrence of lameness during the study lactation in 2 New York dairy herds (row percentages are in parentheses).

\begin{tabular}{|c|c|c|c|c|c|c|c|c|c|}
\hline \multirow[b]{2}{*}{ Diagnosis } & \multicolumn{8}{|c|}{ Days in milk } & \multirow[b]{2}{*}{ Total } \\
\hline & \multicolumn{2}{|c|}{$\leq 60$} & \multicolumn{2}{|c|}{61 to 120} & \multicolumn{2}{|c|}{121 to 240} & \multicolumn{2}{|c|}{$>240$} & \\
\hline & & & & $=\mathrm{N}$ & & & & & \\
\hline Foot rot & 71 & $(58.7)$ & 18 & (14.9) & 21 & (17.4) & 11 & $(9.1)$ & 121 \\
\hline Foot warts & 70 & (26.7) & 81 & $(30.9)$ & 79 & $(30.2)$ & 32 & (12.2) & 262 \\
\hline Sole ulcer & 64 & (26.4) & 77 & (31.8) & 76 & (31.4) & 25 & (10.3) & 242 \\
\hline Multiple diag. ${ }^{1}$ & 5 & $(50.0)$ & 0 & $(0.0)$ & 5 & $(50.0)$ & 0 & $(0.0)$ & 10 \\
\hline Other lameness & 273 & $(47.3)$ & 118 & $(20.5)$ & 111 & (19.2) & 75 & (13.0) & 577 \\
\hline All lameness & 483 & (39.9) & 294 & $(24.3)$ & 292 & $(24.1)$ & 143 & (11.8) & 1212 \\
\hline
\end{tabular}

${ }^{1}$ Multiple diagnoses (among foot rot, foot warts, and sole ulcer) recorded for first lameness event. Cows with multiple other diagnoses are included in "other lameness." 
Table 3. Hazard ratios (HR) and 95\% confidence intervals for the time-independent variables: projected milk yield (M305), parity, and calving season (from the proportional hazards model for the effect of any lameness on culling).

\begin{tabular}{lcc}
\hline Variable & HR & $95 \%$ CI \\
\hline Projected 305-d milk, kg & & \\
Missing & 2.6 & $1.8-3.7$ \\
$\leq 6356$ & 15.4 & $11.7-20.1$ \\
6357 to 7264 & 5.3 & $4.0-7.1$ \\
7265 to 8172 & 3.7 & $2.7-5.0$ \\
8173 to 9080 & 2.4 & $1.8-3.3$ \\
$>9080^{1}$ & 1.0 & $\ldots$ \\
Parity & & \\
$1^{1}$ & 1.0 & $\ldots$ \\
2 & 3.3 & $2.6-4.1$ \\
3 & 4.0 & $3.2-5.1$ \\
$\geq 4$ & 5.2 & $4.2-6.4$ \\
Calving season & & \\
Dec-Feb & 1.0 & $\ldots$ \\
Mar-May & 1.1 & $0.8-1.4$ \\
Jun-Aug & 0.7 & $0.5-0.8$ \\
Sep-Nov & 0.6 & $0.5-0.8$ \\
\hline
\end{tabular}

${ }^{1}$ Baseline category. diseases were found to be unimportant confounding variables because they did not seem to affect the hazard ratios substantially when removed in a step-wise fashion from the models. Therefore, they were not included in the models for which results are presented. The baseline group was defined as those without lameness at each time (hazard ratios for culling of 1.0). From these results it was inferred that lame cows were generally at a greater or equal risk of being culled than the baseline group but were never at a reduced risk of being culled compared with baseline cows.

Effect of lameness on culling tended to vary across time, and depended on the stage of lactation when lameness was diagnosed and on the stage of lactation when culling occurred (Table 4). The lameness effect on culling in the first 60 DIM was low in all models, none differing from the baseline group. Cows diagnosed with lameness during the first 60 DIM seemed to be at greatest risk of being culled between 121 and 240 DIM. This trend was evident in all models. Cows diagnosed with lameness between 61 and 120 DIM had the greatest risk of culling in that period in models 1,2 , and 4 . In the other 2 models, cows were at no more of a significant

Table 4. Summary of the 5 models with hazard ratios (HR) and $95 \%$ confidence intervals for effects of lameness on culling. All models were corrected for projected milk yield, calving season, parity, and other lameness categories (for individual lameness diagnoses in models 2 to 5 ).

\begin{tabular}{|c|c|c|c|c|c|c|c|c|c|c|}
\hline \multirow[b]{3}{*}{ Model } & \multirow{3}{*}{$\begin{array}{l}\text { Lameness } \\
\text { category }\end{array}$} & \multirow[b]{3}{*}{ Interval, $\mathrm{d}$} & \multicolumn{8}{|c|}{ Time interval of culling (days postcalving) } \\
\hline & & & \multicolumn{2}{|c|}{$\leq 60$} & \multicolumn{2}{|c|}{61 to 120} & \multicolumn{2}{|c|}{121 to 240} & \multicolumn{2}{|c|}{$>240$} \\
\hline & & & $\mathrm{HR}$ & $95 \% \mathrm{CI}$ & HR & $95 \% \mathrm{CI}$ & $\mathrm{HR}$ & $95 \% \mathrm{CI}$ & HR & $95 \% \mathrm{CI}$ \\
\hline 1 & $\begin{array}{l}\text { Lameness } \\
\text { (all } \\
\text { diagnoses) }\end{array}$ & $\begin{array}{l}\text { None }^{1} \\
\leq 60 \\
61 \text { to } 120 \\
121 \text { to } 240 \\
>241\end{array}$ & $\begin{array}{l}1.0 \\
1.1\end{array}$ & $0.8-1.7$ & $\begin{array}{l}1.0 \\
1.3 \\
2.0\end{array}$ & $\begin{array}{l}0.8-1.9 \\
1.1-3.7\end{array}$ & $\begin{array}{l}1.0 \\
2.0 \\
1.7 \\
1.7\end{array}$ & $\begin{array}{c}1.4-2.9 \\
1.1-2.7 \\
0.9-2.9 \\
\ldots\end{array}$ & $\begin{array}{l}1.0 \\
1.3 \\
1.5 \\
2.0 \\
1.3\end{array}$ & $\begin{array}{l}0.9-2.0 \\
1.0-2.3 \\
1.3-3.0 \\
0.7-2.3\end{array}$ \\
\hline 2 & Foot rot & $\begin{array}{l}\text { None }^{1} \\
\leq 60 \\
61 \text { to } 120 \\
121 \text { to } 240 \\
>241\end{array}$ & $\begin{array}{l}1.0 \\
1.4\end{array}$ & $0.7-2.8$ & $\begin{array}{l}1.0 \\
1.0 \\
5.1\end{array}$ & $\begin{array}{l}0.4-2.6 \\
1.6-16.2\end{array}$ & $\begin{array}{l}1.0 \\
1.3 \\
2.5 \\
3.0\end{array}$ & $\begin{array}{l}0.7-2.7 \\
0.8-8.0 \\
0.9-9.5\end{array}$ & $\begin{array}{l}1.0 \\
0.6 \\
0.4 \\
1.8 \\
0.2\end{array}$ & $\begin{array}{l}0.2-1.9 \\
0.1-1.8 \\
0.6-5.7 \\
0.0-1.9\end{array}$ \\
\hline 3 & Foot warts & $\begin{array}{l}\text { None }^{1} \\
\leq 60 \\
61 \text { to } 120 \\
121 \text { to } 240 \\
>241\end{array}$ & $\begin{array}{l}1.0 \\
0.4\end{array}$ & $0.0-2.5$ & $\begin{array}{l}1.0 \\
0.9 \\
0.7\end{array}$ & $\begin{array}{l}0.3-2.8 \\
0.1-5.4\end{array}$ & $\begin{array}{l}1.0 \\
1.4 \\
0.5 \\
0.3\end{array}$ & $\begin{array}{l}0.6-2.9 \\
0.2-1.7 \\
0.0-2.2\end{array}$ & $\begin{array}{l}1.0 \\
0.8 \\
0.9 \\
0.7 \\
2.1\end{array}$ & $\begin{array}{l}0.3-2.1 \\
0.4-1.9 \\
0.3-1.9 \\
0.8-5.2\end{array}$ \\
\hline 4 & Sole ulcer & $\begin{array}{l}\text { None }^{1} \\
\leq 60 \\
61 \text { to } 120 \\
121 \text { to } 240 \\
>241\end{array}$ & $\begin{array}{l}1.0 \\
2.0\end{array}$ & $0.9-4.3$ & $\begin{array}{l}1.0 \\
2.4 \\
2.7\end{array}$ & $\begin{array}{l}1.2-5.0 \\
1.3-6.0\end{array}$ & $\begin{array}{l}1.0 \\
2.6 \\
1.5 \\
1.5\end{array}$ & $\begin{array}{l}1.4-4.9 \\
0.8-3.0 \\
0.8-3.5\end{array}$ & $\begin{array}{l}1.0 \\
1.3 \\
1.9 \\
1.1 \\
2.2\end{array}$ & $\begin{array}{l}0.5-3.1 \\
1.0-3.6 \\
0.5-2.5 \\
0.7-7.1\end{array}$ \\
\hline 5 & Others & $\begin{array}{l}\text { None }^{1} \\
\leq 60 \\
61 \text { to } 120 \\
121 \text { to } 240 \\
>241\end{array}$ & $\begin{array}{l}1.0 \\
1.0\end{array}$ & $0.6-1.6$ & $\begin{array}{l}1.0 \\
0.9 \\
0.9\end{array}$ & $\begin{array}{l}0.5-1.5 \\
0.3-2.8\end{array}$ & $\begin{array}{l}1.0 \\
1.5 \\
1.5 \\
1.2\end{array}$ & $\begin{array}{c}\cdots \\
1.0-2.2 \\
0.8-2.6 \\
0.5-3.0\end{array}$ & $\begin{array}{l}1.0 \\
1.3 \\
1.5 \\
2.8 \\
0.9\end{array}$ & $\begin{array}{l}0.9-2.0 \\
0.8-2.5 \\
1.7-4.5 \\
0.3-2.1\end{array}$ \\
\hline
\end{tabular}

\footnotetext{
${ }^{1}$ Baseline category.
} 
risk of being culled when diagnosed during this period than when compared with nonlame cows. Diagnosis of lameness after 120 DIM tended to show significantly increased risks of culling in models 1 and 5 when compared with baseline cows.

Because the overall number of cases of foot rot, foot warts, and sole ulcers was relatively small, the confidence intervals of models 2 through 4 (Table 4) were wider than in models 1 and 5 . Thus, only a few results in these models were significant. Nonsignificant trends, however, seemed to show that foot rot (model 2) resulted in greater risks for culling, especially for culling occurring in midlactation. Although none of these traits differed from the baseline groups, sole ulcer (model 4) seemed to show similar trends, whereas the hazard ratios for foot warts were generally $<1.0$. In contrast to lameness as a whole (model 1), other diagnoses of lameness (model 5) tended to have their greatest effect on culling toward the end of lactation, with little, if any, effect earlier in lactation.

Importance of accounting for confounding and time dependency was shown by 2 alternate analyses of our data. Using a model without any confounders or timedependent covariates, and programming lameness as time-independent, resulted in a culling hazard ratio for lame cows of $0.8(P<0.001)$ times that of nonlame cows. Running our model with all time-independent covariates, and assuming lameness was also time-independent, gave the result that lame cows had a hazard ratio of being culled of $0.6(P<0.001)$ that of a control cow. Therefore, without the time-dependency element in our model, lameness appeared to be (falsely) protective of culling.

\section{DISCUSSION}

\section{Lameness}

The results presented herein demonstrated that the effect of lameness on culling seemed to depend on the time lameness was diagnosed and the time of culling. In general, lameness was associated with a short-term increase in culling rate between 61 and 120 DIM and also toward the end of lactation. There were trends indicating that foot rot and sole ulcers decreased survival. We did not find evidence for a significant effect of foot warts on culling.

Lameness as a whole seemed to have the greatest effect on culling in mid- to late lactation. This is likely to be a direct response to the debilitating effect of lameness or perhaps due to indirect effects of reduced milk yield or poor fertility. Lameness occurring late in lactation (>240 DIM) had a smaller association with culling, perhaps as the effects on reduced milk yield are quantitatively less severe and pregnancy status may have been confirmed. Therefore, the risk of culling when lameness is diagnosed toward the end of lactation may represent more accurately the direct effect of lameness on culling, as its combined effect on other diseases, fertility, and production is less pronounced during this period.

The effect of foot rot on culling seemed greatest when it was diagnosed between 61 and 120 DIM and culling occurred during the same period. This might indicate that foot rot occurring at this time may have had a more noticeable effect on the cow's health and production. Because the breeding period starts in the first third of lactation, and peak milk yield also occurs during this period, any effect of disease on these indices would be greatest during these periods, which therefore may increase the risk of such cows being culled. Foot rot occurring at the start or end of lactation seemed to have little effect on culling during most of the lactation, which is somewhat paradoxical, but may reflect lesser effects on milk yield and fertility during this time or that foot rot is generally less severe during this period. Studies with larger sample sizes would likely provide more precise estimates and may help to clarify this issue.

Sole ulcers tended to have their main significant effect on culling during midlactation, again indicating that they may have affected milk yield and reproductive indices during this period. Sole ulcers diagnosed early and late in lactation had little effect on culling. Other diagnoses of lameness only seemed to have an increased hazard toward the end of lactation, perhaps suggesting reduced effects of such lameness on other health, fertility, and production traits when compared with results from models 1 to 4 (Table 4).

The results of our study apply to cows diagnosed lame at least once during lactation. We analyzed the overall effect of lameness and diagnosis-specific effects, but did not investigate whether repeated lameness diagnoses or increased severity would further increase the risk of culling. The characteristics of the 2 study herds should be considered when applying these results to other dairy farms. For example, these herds were housed in free-stall barns having concrete floors, and cows were fed a TMR and kept without access to pasture or dirt lots. These results should be applicable to similar herds particularly in upper Midwest or Northeast US in which climate, housing, feeding, and management practices may be comparable.

It must be noted that at each stage of lactation, comparisons were only made within that stage because the baseline group may have differed among stages. Culling risk for cows is greatest at the start and end of lactation (Beaudeau et al., 1994; Gröhn et al., 1997). Therefore, our baseline (nonlame) cows had a high risk of culling 
toward the beginning and end of lactation. This influences the interpretation of our results (e.g., the hazard ratio of sole ulcer diagnosed $\leq 60$ DIM for culling between 61 and 120 DIM was 2.4 and for culling between 121 and 240 DIM was 2.6; Table 4). The hazard ratios of 2.4 and 2.6 are not directly comparable and should not be interpreted to mean that cows during later lactation were only slightly more likely to be culled than during early lactation. It does mean that in the first time period, cows were at 2.4 times greater risk of being culled than baseline cows during that period, whereas in the second time period, cows were 2.6 times as likely to be culled as baseline cows during that period only. Therefore, results from different time periods cannot be compared with each other, only to baseline values from that period.

\section{Comparison with Other Studies}

Survival analysis methods are useful when the response variable is time to an event. Some survival analysis models allow the inclusion of time-dependent covariates that have effects on survival that vary over time (Cantor, 1997). A comparison of culling models without time-dependent covariates and with time-dependent covariates found that models without time dependency tended to seriously underestimate the risk of a disease on culling (Gröhn et al., 1997). This was because in models without time-dependent covariates, the risk was averaged over the whole lactation (i.e., the risk for culling was assumed to be equal across lactation, even before any diseases occurred-which is conceptually hard to believe).

As in other models (Rajala-Schultz and Gröhn, 1999a, c), the addition of calving season, parity, and M305 into our model increased its goodness of fit (measured by comparing the ratios of log likelihoods of the respective models with the $\chi^{2}$ distribution; results not shown). Conceptually, these variables could all be considered as confounders and not intervening variables, and hence, should have improved the accuracy of our model. As expected, older cows, and cows producing less milk, especially those in the lowest production category, had an increased risk of culling. These findings were consistent with another study in New York herds (Gröhn et al., 1998) and with results in Canadian dairy herds (Dohoo and Martin, 1984).

Our results on lameness generally support those of Dohoo and Martin (1984), who used discriminate analysis, and found that lameness was associated with an increased risk of culling early in lactation, and that this risk tended to decrease with time. Rajala-Schultz and Gröhn (1999a) used Cox's model and found that lameness had a significant effect on culling throughout the whole lactation, although this risk was greatest during the first half of lactation. These results were of a similar pattern and magnitude to ours. When forcing into the model the effects of milk yield (Rajala-Schultz and Gröhn, 1999c), effects of lameness on culling increased only slightly, but decreased somewhat when pregnancy status and number of inseminations were included (Rajala-Schultz and Gröhn, 1999b). It must be noted that fertility is unlikely to be a confounder, unless it has a direct effect on incidence of lameness and so is more likely to be an intervening variable. Therefore, by including fertility indices in such a model, it seemingly reduces the effect of lameness on culling because it removes the effects of lameness on fertility indices.

Beaudeau et al. (1994) found no effect of lameness on culling in a logistic regression analysis when culling was a time-dependent covariate. However, that the diseases were input as time-independent variables and the model was controlled for fertility may have reduced the overall effect of lameness on culling. A further study conducted using Cox's model (Beaudeau et al., 1995), in which all disease covariates were time-dependent, also failed to find a significant effect of lameness on culling. The inclusion of fertility indices, such as reproduction status and abortion, in the model may have affected the results.

In analyses where confounders were not controlled, mixed results have been detected. Significantly more lame cows were culled compared with nonlame controls in a sample of 17 English herds (Collick et al., 1989). Similar results were reported by Milian Suazo et al. (1988), who found that lameness often caused "forced" (involuntary) culling soon after diagnosis, which was particularly costly to the farmer. Barkema et al. (1994) reported that fewer lame cows were culled compared with controls in a survey of 13 Dutch dairy herds.

It seems unlikely that lame cows are less likely to be culled than control cows because lameness has effects on production, fertility, and possibly other diseases (although none we investigated were found to be confounding). In addition, a lame cow cannot be culled before it becomes lame, and its hazard of culling before lameness occurs is low because the cow has (by definition) survived until onset of lameness. The risk of culling due to lameness is likely to be greatly underestimated unless time dependency of both lameness and culling is taken into account in a model. This is because such a model will presume the risk of culling for a lame cow is equal across time, even before onset of lameness. This effect was demonstrated by our 2 alternative analyses where time dependency was ignored resulting in culling HR estimates for lameness of 0.8 and 0.6 . 


\section{CONCLUSIONS}

This analysis has shown that the effect of lameness (and other diseases) on the decision to cull varies across lactation and so must be analyzed in a time-dependent manner. In our analyses, lameness was programmed as time-dependent, whereas other confounding covariates (parity, calving season, and milk yield) were programmed as time-independent. Lameness tended to either increase the risk of a cow being culled or had no effect on this risk when compared with nonlame cows. That risk depended on the specific diagnosis of lameness, time of diagnosis, and time of culling. In contrast to some previous reports, lameness was never protective of culling in these analyses.

\section{ACKNOWLEDGMENTS}

We thank the owners and employees of the participating farms. We also thank Julia A. Hertl for essential technical and software assistance and Naomi J. Cambridge for discussions and valuable input to this paper. This material is based upon work supported by the Cooperation State Research, Education and Extension Service, USDA, Section 1433 Animal Health and Disease Research Program. The first author was supported by the Wellcome Trust (grant no. 067812/Z/02/Z) as part of Cornell University's Leadership Program for Veterinary Students.

\section{REFERENCES}

Barkema, H. W., J. D. Westrik, K. A. S. van Keulen, Y. H. Schukken, and A. Brand. 1994. The effects of lameness on reproductive performance, milk production and culling in Dutch dairy farms. Prev. Vet. Med. 20:249-259.

Beaudeau, F., V. Ducrocq, C. Fourichon, and H. Seegers. 1995. Effect of disease on length of productive life of French Holstein dairy cows assessed by survival analysis. J. Dairy Sci. 78:103-117.

Beaudeau, F., K. Frankena, C. Fourichon, B. Seegers, B. Faye, and J. P. T. M. Noordhuizen. 1994. Associations between health disorders of French dairy cows and early and late culling within the lactation. Prev. Vet. Med. 19:213-231.

Cantor, A. 1997. Extending SAS Survival Analysis Techniques for Medical Research. SAS Inst. Inc., Cary, NC.

Clarkson, M. J., D. Y. Downham, W. B. Faull, J. W. Hughes, F. J. Manson, J. B. Merritt, R. D. Murray, W. B. Russell, J. E. Sutherst, and W. R. Ward. 1996. Incidence and prevalence of lameness in dairy cattle. Vet. Rec. 138:563-567.

Collick, D. W., W. R. Ward, and H. Dobson. 1989. Associations between types of lameness and fertility. Vet. Rec. 125:103-106.

Cox, D. R. 1972. Regression models with life-tables (with discussion). J. R. Stat. Soc. Ser. B. 34:187-202.

Dohoo, I. R., and S. W. Martin. 1984. Disease, production and culling in Holstein-Friesian cows. V. Survivorship. Prev. Vet. Med. 2:771-784.

Ducrocq, V., and J. Sölkner. 1994. The Survival Kit: A FORTRAN package for the analysis of survival data. Pages 51-52 in Proc. 5th World Congr. Genet. Appl. Livest. Prod., Guelph, Ontario, Canada.

Ducrocq, V., and J. Sölkner. 1998. The Survival Kit V3.0: A package for large analyses of survival data. Pages 447-448 in Proc. 6th World Congr. Genet. Appl. Livest. Prod., Armidale, NSW, Australia.

Eddy, R. G., and C. P. Scott. 1980. Some observations on the incidence of lameness in dairy cattle in Somerset. Vet. Rec. 106:140-144.

Esslemont, R. J., and M. A. Kossaibati. 1996. Incidence of production diseases and other health problems in a group of dairy herds in England. Vet. Rec. 139:486-490.

Esslemont, R. J., and M. A. Kossaibati. 1997. Culling in 50 dairy herds in England. Vet. Rec. 140:36-39.

Gröhn, Y. T., V. Ducrocq, and J. A. Hertl. 1997. Modeling the effect of disease on culling: An illustration of the use of time-dependent covariates in survival analysis. J. Dairy Sci. 80:1755-1766.

Gröhn, Y. T., S. W. Eicker, V. Ducrocq, and J. A. Hertl. 1998. Effect of diseases on the culling of Holstein dairy cows in New York State. J. Dairy Sci. 81:966-978.

Hernandez, J., J. K. Shearer, and D. W. Webb. 2001. Effect of lameness on the calving to conception interval in dairy cows. JAVMA 218:1611-1614.

Lee, L. A., J. D. Ferguson, and D. T. Galligan. 1989. Effect of disease on days open assessed by survival analysis. J. Dairy Sci. 72:1020-1026.

Leech, F. B., M. E. Davis, and W. D. Macrae. 1960. Disease, Wastage and Husbandry in the British Dairy Herd 1957-58. HMSO, London, United Kingdom.

Lucey, S., G. J. Rowlands, and A. M. Russell. 1986. The association between lameness and fertility in dairy cows. Vet. Rec. 118:628-631.

McLennan, M. W. 1988. Incidence of lameness requiring veterinary treatment in dairy cattle in Queensland. Aust. Vet. J. 65:144-147.

Milian-Suazo, F., H. N. Erb, and R. D. Smith. 1988. Descriptive epidemiology of culling in dairy cows from 34 herds in New York State. Prev. Vet. Med. 6:243-251.

Prentice, D. E., and P. A. Neal. 1972. Some observations on the incidence of lameness in dairy cattle in west Cheshire. Vet. Rec. 91:1-7.

Rajala-Schultz, P. J., and Y. T. Gröhn. 1999a. Culling of dairy cows. I. Effects of diseases on culling in Finnish Ayrshire cows. Prev. Vet. Med. 41:195-208.

Rajala-Schultz, P. J., and Y. T. Gröhn. 1999b. Culling of dairy cows. II. Effects of diseases and reproductive performance on culling in Finnish Ayrshire cows. Prev. Vet. Med. 41:279-294.

Rajala-Schultz, P. J., and Y. T. Gröhn. 1999c. Culling of dairy cows. III. Effects of diseases, pregnancy status and milk yield on culling in Finnish Ayrshire cows. Prev. Vet. Med. 41:295-309.

Rajala-Schultz, P. J., Y. T. Gröhn, and C. E. McCulloch. 1999. Effects of milk fever, ketosis, and lameness on milk yield in dairy cows. J. Dairy Sci. 82:288-294.

StatXact 3 for Windows User Manual. 1996. Cytel Software Corporation, Cambridge, MA.

Van Arendonk, J. A. M. 1985. Studies on the replacement policies in dairy cattle. II. Optimum policy and influence of changes in production and prices. Livest. Prod. Sci. 13:101-121.

Van Arendonk, J. A. M., and A. A. Dijkhuizen. 1985. Studies on the replacement policies in dairy cattle. III. Influence of variation in reproduction and production. Livest. Prod. Sci. 13:333-349.

Warnick, L. D., D. Janssen, C. L. Guard, and Y. T. Gröhn. 2001. The effect of lameness on milk production in dairy cows. J. Dairy Sci. 84:1988-1997.

Webster, J. 1986. Health and welfare of animals in modern husbandry systems: Dairy cattle. In Pract. 8:85-89.

Whitaker, D. A., J. M. Kelly, and S. Smith. 2000. Disposal and disease rates in 340 British dairy herds. Vet. Rec. 146:363-367. 